\title{
Re-Emerging Foci of Visceral Leishmaniasis in Armenia - First Molecular Diagnosis of Clinical Samples
}

\begin{tabular}{|c|c|}
\hline Journal: & Parasitology \\
\hline Manuscript ID & PAR-2018-0339.R1 \\
\hline Manuscript Type: & Research Article \\
\hline $\begin{array}{r}\text { Date Submitted by the } \\
\text { Author: }\end{array}$ & 21-Dec-2018 \\
\hline Complete List of Authors: & $\begin{array}{l}\text { Sukiasyan, Anna; Research Institute of Epidemiology, Virology and } \\
\text { Medical Parasitology after A.B. Alexanyan, Ministry of Health, } \\
\text { Epidemiology, Virology and Medical Parasitology; Medical Faculty of the } \\
\text { Yerevan Haybusak University, Department of Biology and Pathology } \\
\text { Keshishyan, Ara; Research Institute of Epidemiology, Virology and } \\
\text { Medical Parasitology after A.B. Alexanyan, Ministry of Health, } \\
\text { Epidemiology, Virology and Medical Parasitology } \\
\text { Manukyan, Dezdemonia; Research Institute of Epidemiology, Virology } \\
\text { and Medical Parasitology after A.B. Alexanyan, Ministry of Health, } \\
\text { Epidemiology, Virology and Medical Parasitology } \\
\text { Melik-Andreasyan, Gayane; Research Institute of Epidemiology, Virology } \\
\text { and Medical Parasitology after A.B. Alexanyan, Ministry of Health , } \\
\text { Epidemiology, Virology and Medical Parasitology } \\
\text { Atshemyan, Liana; Research Institute of Epidemiology, Virology and } \\
\text { Medical Parasitology after A.B. Alexanyan, Ministry of Health, } \\
\text { Epidemiology, Virology and Medical Parasitology } \\
\text { Apresyan, Hripsime; Yerevan State Medical University after Mkitar } \\
\text { Heratsi, Medical Parasitology } \\
\text { Strelkova, Margarita; Martsinovsky Institute of Medical Parasitology, } \\
\text { Sechenov First Moscow State Medical University, Moscow, Russion } \\
\text { Federation, Tropical and Vector-Born Diseases } \\
\text { Frohme, Marcus; Technische Fachhochschule Wildau, Molekulare } \\
\text { Biotechnologie und Funktionelle Genomik } \\
\text { Cortes, Sofia; Instituto de Higiene e Medicina Tropical, Unidade de } \\
\text { Parasitologia Médica } \\
\text { Kuhls, Katrin; Technische Fachhochschule Wildau, Molecular } \\
\text { Biotechnology and Functional Genomics }\end{array}$ \\
\hline Key Words: & $\begin{array}{l}\text { Visceral leishmaniasis, Molecular diagnosis, Molecular typing, Armenia, } \\
\text { Southern Caucasus region, Leishmania infantum, Emerging infectious } \\
\text { diseases, Neglected tropical diseases }\end{array}$ \\
\hline
\end{tabular}

\section{SCHOLARONE Manuscripts}




\title{
Re-Emerging Foci of Visceral Leishmaniasis in Armenia - First Molecular Diagnosis of Clinical Samples
}

Running title: Visceral leishmaniasis in Armenia

\begin{abstract}
Anna Sukiasyan a,b1, Ara Keshishyan ${ }^{\mathrm{a}}$, Dezdemonia Manukyanª, Gayane Melik-Andreasyan ${ }^{\mathrm{a}}$, Liana Atshemyan ${ }^{\mathrm{a}}$, Hripsime Apresyan ${ }^{\mathrm{c}}$, Margarita Strelkovad ${ }^{\mathrm{d}}$, Marcus Frohme ${ }^{\mathrm{b}}$, Sofia Cortes $^{\text {bee, }, \text { and Katrin Kuhls }}$ b* $^{*}$
\end{abstract}

a Research Institute of Epidemiology, Virology and Medical Parasitology after A.B. Alexanyan, Ministry of Health, 1 Khudyakov St., 0063, Yerevan, Armenia

b Division Molecular Biotechnology and Functional Genomics, Technical University of Applied Sciences Wildau, Hochschulring 1, 15745 Wildau, Germany

c Yerevan State Medical University after Mkitar Heratsi, 2 Koryun str., 0025, Yerevan, Armenia

d Martsinovsky Institute of Medical Parasitology, Tropical and Vector-Born Diseases, Sechenov First Moscow State Medical University, Malaya Pirogovskaya 20, 119830 Moscow, Russion Federation

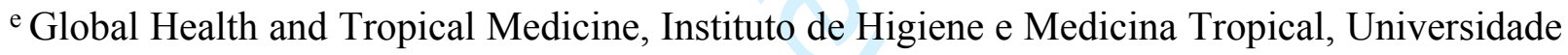
Nova de Lisboa, Rua da Junqueira No 100, 1349-008 Lisboa, Portugal

*corresponding author's address: Dr. Katrin Kuhls, Molekulare Biotechnologie und Funktionelle Genomik, Technische Hochschule Wildau, Hochschulring 1, 15745 Wildau, Germany. Email: Katrin.Kuhls@th-wildau.de; phone: +49 (0) 3375 508-372, fax: +49 (0) $3375508-260$

${ }^{1}$ Current affiliation: Department of Biology and Pathology, Medical Faculty of the Yerevan Haybusak University, Yerevan, Armenia

${ }^{2}$ Current affiliation: Global Health \& Tropical Medicine, Global Health and Tropical Medicine, Instituto de Higiene e Medicina Tropical, UNL, Lisbon, Portugal 


\begin{abstract}
Visceral leishmaniasis (VL) was firstly reported in Armenia in 1913. Following a considerable increase of the number of cases until the mid 1950s, the diseases disappeared after 1969 and reemerged in 1999. Scientific literature about VL in Armenia is available only in Russian or Armenian. This paper presents a historical overview about leishmaniasis in Armenia based on this literature as well as an epidemiological update since the re-emergence of the disease. In 1999- 2016, 116 indigenous VL cases were recorded mainly in children in 8 of the 11 districts, however VL is underreported because of lack of trained medical personal and diagnostic facilities. The aim of this work was to apply for the first time molecular diagnosis of VL in Armenia. Out of $25 \mathrm{VL}$ suspected patients, 22 were positive by microscopy and PCR. Genotyping using ITS1-PCR-RFLP and sequencing identified the causative agent of VL in Armenia as Leishmania infantum. The present work is an important step towards the inclusion of molecular techniques in the current diagnosis of VL in Armenia and the establishment of local molecular diagnostic facilities.
\end{abstract}

\title{
KEY WORDS
}

Visceral leishmaniasis, molecular diagnosis, molecular typing, Armenia, Southern Caucasus region, Leishmania infantum, emerging infectious diseases, neglected tropical diseases 


\section{INTRODUCTION}

A total of 98 countries on five continents are endemic for leishmaniasis with 350 million people at risk and annual estimates of 0.3 million cases of visceral leishmaniasis (VL) and 1 million cases of cutaneous leishmaniasis (CL). Visceral leishmaniasis is the most severe form, fatal if not treated, with about 20,000-50,000 deaths each year (WHO, 2015). Treatment of VL is based on chemotherapy, but available drugs present severe side effects. Frontline treatment relies on pentavalent antimonials and also on amphotericin B. Miltefosine was the first oral drug to treat VL but its use is limited due to its known teratogenic effects and to selection of resistance (Croft \& Olliaro, 2011).

The causative agents of leishmaniasis are protozoan parasites of the genus Leishmania, transmitted by different sand fly species. Visceral leishmaniasis is caused, with few exceptions, by two species belonging to the Leishmania donovani complex, L. donovani and L. infantum. The transmission of the first species is mainly anthroponotic, whereas the transmission of the latter is zoonotic with a variety of canids known to serve as animal reservoirs and the domestic dog as the main reservoir host (Akhoundi et al., 2016; Millan et al., 2014; Ready, 2014).

Conventional VL diagnosis is performed by parasitological methods as visualization of Leishmania parasites by microscopy in Giemsa-stained smears of bone marrow, lymph node or spleen aspirates or setting up parasite cultures from bone marrow aspirates or buffy coat. Other approaches are based on serology and the mostly used methods are the immunofluorescence antibody test (IFAT), the enzyme-linked immunosorbent assay (ELISA), the direct agglutination test (DAT) and the immunochromatographic strip test (rK39) (WHO, 2010). The serological tests have the limitation that they cannot distinguish between current, subclinical and past infections. The most powerful diagnostic tools in terms of sensitivity and specificity are PCRbased methods however, they are restricted to research centres and specialized laboratories (Akhoundi et al., 2017). They are superior to serological methods, as well as microscopy or culture, especially for samples with low parasitic loads and they can be performed on peripheral blood, sampling of which is less invasive than biopsies.

\section{Historical overview of Leishmaniasis in Armenia}

Visceral leishmaniasis was well-known to the physicians in the Imperial Russia who worked in the Caucasus region and in Central Asia since the mid of the $19^{\text {th }}$ century. In the time of the Soviet Union the etiology, pathogenesis and epidemiology of this disease was intensively studied by famous local researchers who made many important conclusions on the biology of the causative agents and vectors as well as the transmission cycles. After the dissolution of the 
Soviet Union in 1991, VL received less attention and the new independent republics had to readjust their medical and public health services (Strelkova et al., 2015). Zoonotic VL currently occurs in many former Soviet Union countries such as in Georgia, Azerbaijan, Tajikistan and Uzbekistan being a serious public health concern (Alvar et al., 2012; Babuadze et al., 2014; Kovalenko et al., 2011; Strelkova et al., 2015).

Leishmaniasis historically holds a special place in infectious pathologies of Armenia, however most historical and present publications are in Russian or Armenian and therefore not accessible for the majority of international scientists and clinicians. Only a single information in English on VL in Armenia can be found in a recent review (Strelkova et al., 2015). In the past both VL and CL were recorded in Armenia. Interestingly, the first detailed description of the organism causing oriental sores (later named Leishmania tropica) by the American pathologist J. H. Wright in 1903 was based on clinical material isolated from sores of an Armenian girl that came to America (Steverding, 2017; Wright, 1903). Anthroponotic cutaneous leishmaniasis (ACL) was registered for the first time in 1920 in the Shirak district at the north-western border of the country (Isahakyan, 1924). According to historical data a total of $135 \mathrm{CL}$ cases were recorded between 1938 and 1970, mainly in the cities Kapan and Goris (Karagezian, 1966; Mirzoyan, 1941; Pirumov, 1957). By the mid-1960s by combining treatment of patients and insecticidal treatment in the cities with ACL, almost complete elimination of this form of leishmaniasis was achieved. Zoonotic cutanous leishmaniasis (ZCL) was never recorded in Transcaucasia. Since 1999 neither local nor imported cases of CL were detected.

Visceral leishmaniasis was registered for the first time in the Southern Caucasus region (Georgia, Armenia and Azerbaijan) in 1912/1913 in four children including a girl from Yerevan (Gurko, 1913). The second report about VL in Armenia in a 6-years-old girl was published in 1925 (Gishgorn, 1925). Since that time many cases were found predominantly in children under the age of 13 years, with almost half of the cases occurring in 1-2 years old children. The first adult case was detected in 1947 in a 23-years-old woman (Karapetyan, 1949), and only two more cases occurred in adults until 1959. Between 1926 and 1969 a total of 919 VL cases were registered in 62 villages from 16 districts of the country. The most active focus was Yerevan with $81.1 \%$ of the cases (Karapetyan, 1972). Especially in the early 1950s the number of VL cases increased not only in Armenia, but also in other Southern Caucasus countries, most probably because of new human settlements in former rural regions. Phlebotomus kandelaki and $P h$. balcanicus, widely distributed in regions between 400 and $700 \mathrm{~m}$, were identified as potential vectors for L. infantum in the Caucasus region including Armenia (Baranets et al., 2011; Darchenkova \& Dergacheva, 1989; Dergacheva \& Oganesian, 1987; Karapetyan \& 
Baghdasaryan, 1972; Saladze, 1964). Evidence of Ph. kandelaki and Ph. balcanicus infected by L. infantum was provided for the first time only recently in 2012 by the use of PCR-based methods for sand flies from Georgia (Giorgobiani et al., 2012).

In the first reservoir study in Armenia that was carried out in 1920 three dogs from Yerevan were found to be infected (Mamikonyan, 1935). Later a high number of sick dogs was registered in Yerevan, as well as in five other districts (Mamikonyan, 1935). Further surveys were carried out between 1954 and 1970 with a total of 4109 examined animals (e.g. dogs, cats, foxes, wolves, and rodents) and $3.8 \%$ of the dogs were found to be infected with Leishmania sp. from localities with human VL cases. All the infected dogs originated from localities with human VL cases. According to these and other studies, the main wild reservoirs of VL in Armenia were foxes, jackals and wolves (Karapetyan \& Baghdasaryan, 1970; Karapetyan \& Baghdasaryan, 1972). Although the parasites were not definitely identified to the species level, clinical and epidemiological data suggested that it was L. infantum (Karapetyan \& Baghdasaryan, 1972; Karapetyan et al., 1960).

Since the mid-1950s and in the 1960s the number of VL cases was significantly reduced in the USSR as a result of wide-scale implementation of activities on trapping and culling sick dogs as well as conducting massive spraying campaigns for malaria control with significant reduction of sand fly populations (Isaev, 1959; Isaev \& Ryabtsev, 1958). Specifically in Armenia there was a control program conducted in 1954-55 in the city of Yerevan that reduced significantly the morbidity from VL (Karapetyan et al., 1960). As a result of further control measures between 1954 and 1969 the number of VL cases continuously decreased (1953-55 -73, 50, 39 cases, respectively; 1964 - two cases; 1967 and 1968 one case per year) with the last registered case in 1969 (Karapetyan et al., 1970).

\section{Re-emergence of the disease}

In 1999, after a long period without any notification, a VL case was diagnosed in a 4-yearsold child from the village Shnogh in the Lori district. Between 1999 and 2016, 116 indigenous and 99 imported cases of VL were recorded in the country mainly in the districts Syunik, Tavush and Lori (Paronyan et al., 2015; Sukiasyan et al., 2017) (Figure 1), some of them were included in the present study. According to entomological monitoring during this time period an increase in vector populations of Ph. balcanicus, Ph. kandelaki and Ph. papatasi was observed, particularly in the capital Yerevan, but also in the Ararat valley, Lori and Syunik districts (Keshishyan \& Manukyan, 2003). In the Republic of Nagorno-Karabakh 82 cases of VL were 
registered between 2004 and 2013, mainly in Kashatagh, Hadrut and Stepanakert, of which 90.2 $\%$ were children under 14 years old (Keshishyan et al., 2013a). Until now there was no case of Leishmania/HIV co-infection in Armenia (unpublished data). Treatment for VL patients is free with meglumine antimoniate $\left(\right.$ Glucantime $\left.^{\circledR}\right)$.

The current trend of increasing numbers of VL is being observed in different countries of the Southern Caucasus, especially in Georgia and Azerbaijan. In the last two decades, the annual number of clinical VL cases in Georgia has remained persistently high, and varies between 122 and 189 (Babuadze et al., 2014). Also in Azerbaijan the estimated annual incidence of VL is high, ranging from 60 to 110 cases (Alvar et al., 2012; Strelkova et al., 2015). Nevertheless, underreporting is suspected especially in Armenia and Azerbaijan, because of low awareness among the local population and physicians, lack of leishmaniasis diagnosis training programs for medical personnel and frequent misdiagnosis.

\section{Diagnostic methods in use}

Presently all suspected VL cases are reported to and all diagnostic examinations are carried out in the Research Institute of Epidemiology, Virology and Medical Parasitology named after A.B. Alexanyan, Ministry of Health, Yerevan and the Reference Laboratory Center of the National Center for Disease Control and Prevention in Yerevan. Diagnosis of VL in Armenia was based, until the start of this study in 2015, exclusively on the clinical picture and the demonstration of parasites in Giemsa-stained smears from bone marrow aspirates by microscopic examination. Only from 2015 on serological tests as ELISA and rK39 were continuously implemented. Also setting up cultures from clinical material was not possible. The reasons of that was the lack of qualified personnel trained in modern diagnostic methods as well as of reference laboratories with the necessary equipment. Microscopy and serology however present limitations in terms of sensitivity and specificity. Since endemic foci of VL are re-emerging in Armenia after a long hiatus, there is a need of early, fast and reliable detection of infections. PCR-based methods are commonly used for diagnostic purposes (Akhoundi et al., 2017), as they are highly sensitive and specific and molecular typing allows species identification and discrimination of Leishmania at strain level, depending on the markers used and many key epidemiological questions can be addressed (Akhoundi et al., 2017; Schonian et al., 2011). The aim of the present work was the implementation of molecular methods for diagnosis of VL in Armenia and to enable the identification of the causative Leishmania species.

\section{Material ANd Methods}




\section{Study area, human cases, samples and conventional diagnosis}

Retrospective data on case numbers and geographical distribution of cases presented in Figure 1 are based on the notifications to the Research Institute of Epidemiology, Virology and Medical Parasitology named after A.B. Alexanyan, Ministry of Health, Yerevan. Diagnosis was performed initially on the basis of clinical observations. Bone marrow aspirates were collected from all patients and Giemsa-stained smear slides were prepared for further diagnosis. All slides were analyzed for the presence of amastigotes at 400x and 1000x magnification. Epidemiological data, information about travel histories as well as clinical characteristics were collected from all patients. Cases were considered as indigenous if the patient did not leave Armenia for 1-2 years. If the patients did not live in Armenia for several years and in the nearest epidemic season, the cases were classified as imported ones. Occurrence of putative vectors and of reservoirs in the localities of residence of the patients was examined. VL positive patients were treated with Glucantime or Amphotericin B.

Between 2012 and 2016, all clinically suspected VL patients were hospitalized in the Infectious Clinical Hospital "Nork" in Yerevan, 25 of which were included in this study in which molecular methods for diagnosis were applied. Out of these 25 patients, 14 were male and 11 female with an age range between 1 and 12 years (with the exception of a 51 years old adult). They came from the districts Syunik, Lori, Tavush, Yerevan, Armavir, and Kotayk and did not travel to other countries (Figure 1C, Table 1). The same slides examined by microscopy were used for DNA extraction.

\section{DNA extraction and PCR amplification}

DNA was extracted from stained slides as described elsewhere (Meredith et al., 1993; Schonian et al., 1996). An additional purification step to avoid inhibition was carried out for all clinical samples by using a DNA purification kit (Qiagen). DNA was stored at $-20^{\circ} \mathrm{C}$.

The internal transcribed spacer 1 (ITS1) of the ribosomal DNA was amplified by PCR with primers LITSR and L5.8S (el Tai et al., 2000) including negative, positive and inhibition controls. Negative controls were carried out by using $\mathrm{ddH}_{2} \mathrm{O}$ instead of DNA. In addition negative preparation controls were performed. For inhibition controls DNA (the same amount as for positive control) of L. turanica (IPAP/TM/1991/M87) extracted from culture was added together with the DNA of the analyzed clinical sample. For positive controls DNA of the following WHO reference strains was used: L. infantum MHOM/ES/1993/PM1, L. major MHOM/SU/1973/5ASKH and L. tropica MHOM/SU/1974/SAF-K27. PCR amplification was carried out as described previously, using $10 \mathrm{ng}$ of DNA of the reference strains or $2 \mu \mathrm{l}$ of extracted DNA from clinical samples (el Tai et al., 2000; Schonian et al., 2003). PCR products 
were subjected to electrophoresis in $2 \%$ agarose gels with DNA Stain G (Serva, Germany) in 1x TAE buffer and visualized under ultraviolet light.

\section{Restriction Fragment Length Polymorphism (RFLP) and sequence analysis}

In order to identify Leishmania species, RFLP was performed according to Schönian et al. (Schonian et al., 2003). Depending on band intensity of the respective PCR product in control electrophoresis 10-20 $\mu \mathrm{l}$ of amplified ITS1 PCR products were digested with $10 \mathrm{U}$ of HaeIII at $37{ }^{\circ} \mathrm{C}$ for 2 hours as recommended by the supplier (New England BioLabs Inc., UK). The digested fragments were subjected to electrophoresis in 3.5\% Metaphor agarose gels (SigmaAldrich, Germany) with DNA Stain G in 1x TBE buffer and visualized as previously. The above mentioned strains of $L$. infantum, L. major and L. tropica were used as references and pUC19 (Thermo Fisher Scientific, UK) was used as molecular size standard. The amplified fragments obtained by ITS1-PCR of two of the clinical samples were sequenced (SMB Services in Molecular Biology GmbH, Germany) by using an ABI3130XL sequencer (Applied Biosystems, USA). Sequences were submitted to GenBank (accession numbers LT576161, LT576162).

\section{RESULTS}

Since re-emergence in 1999 the number of VL cases is increasing in Armenia. Figure 1A shows the number of indigenous and imported cases per year for the period 1999-2016, notified to the Research Institute of Epidemiology, Virology and Medical Parasitology named after A.B. Alexanyan, Ministry of Health, Yerevan. In total 215 VL cases were registered in this time period (Figure 1A) - 116 indigenous cases without any travel history outside Armenia and 99 imported VL cases, all originating from Nagorno-Karabakh. The local cases of VL were registered in 8 of the 11 districts of Armenia, mainly in the northern districts Lori (19\%), and Tavush (23\%), in the southern district Syunik (29\%) and in Yerevan (22\%) (Figure 1C). The infective season starts in April with the occurrence of the sand flies and ends in September/October. The seasonal quantitative dynamics of sand flies varies in the different regions of the country. The occurrence of putative vectors and of reservoirs in the localities of residence of the patients has been proven. The epidemic season (highest numbers of cases) can be observed between December till March.

Among the 116 local patients 43 (37.1\%) were female, and 73 (62.9\%) male. The age distribution among these patients was as follows: $86(74.1 \%)$ were children up to three years old, $26(22.4 \%)$ children between 3 and 10 years old and $4(3.4 \%)$ were adults in the age of 21 , 
24, 51 and 54 years. Main clinical symptoms of the 116 indigenous patients were general weakness (100\%), pallor (100\%), splenomegaly (100\%), hepatomegaly (98\%), fever (94\%), lymphadenopathy (86\%), hemorrhagic rash (22\%), bleeding (22\%), sleep disorder (20\%), and consciousness disorder (14\%). The following laboratory data were collected at the time of admission: anemia $100 \%$, Hb mean value $71.68(\mathrm{~g} / \mathrm{L})$, leukopenia $70 \%$, mean value 2.82 $\left(10^{9} / \mathrm{L}\right)$, thrombocytopenia $82 \%$, mean value $74\left(10^{9} / \mathrm{L}\right)$. Pentavalent antimonials (Glucantime) received $95 \%$ of the patients, amphotericin B $5 \%$. The majority of patients recovered, three of them died. Relapses were observed in three cases, which were treated successfully. All imported cases were also successfully treated, and $76 \%$ patients were children up to three years old and $34 \%$ were in the age of 3-10 years. The gender ratio was $61 \%$ males and $39 \%$ females.

Bone marrow samples of 25 VL suspected patients were collected between 2012 and 2016 (Table 1). Twenty-two out of the 25 samples were positive by microscopy, presenting different parasitic loads from highly infected samples till samples with very few parasites. In addition, Leishmania DNA was detected by ITS1-PCR in the same 22 bone marrow samples, showing a $\sim 320$ bp fragment. Inhibition of amplification for the three PCR-negative samples was excluded by inhibition controls. Contamination during DNA preparation or PCR was excluded since no products were observed in the negative controls. Concerning age distribution and gender, most cases were observed in children up to 3 years old $(n=18)$ in an equal gender ratio.

Figure 1C shows the origin and number of studied positive VL cases in Armenia. Most cases were found in the districts Yerevan (5), Syunik (12) and Tavush (5) showing a trend of rather urban occurrence of VL, as the cases were found in large cities from these districts as Yerevan and Kapan.

The causative agent, identified by RFLP of the ITS1-PCR product of the positive samples was L. infantum (Figure 2). The sizes of the restriction products were identical for all clinical samples (184 bp, $72 \mathrm{bp}, 55 \mathrm{bp}$ ). They correspond to those observed for the L. infantum reference strain and are different from those of the L. donovani reference strain (164 bp, $75 \mathrm{bp}$, 54 bp) described previously (Schonian et al., 2003). Since a metaphor agarose gel was applied the size difference of $20 \mathrm{bp}$ in the largest fragment between L. infantum and L. donovani would be detectable and $L$. donovani therefore can be excluded. The ITS1 fragments of samples Arm11 (LT576161) and Arm17 (LT576162) were sequenced and showed $100 \%$ homology to previously sequenced $L$. infantum reference strains (Kuhls et al., 2005). Additional sequencing of the ITS1 region of all L. infantum samples was not useful, since according to published data and own comprehensive experiments there is no variability in this target for L. infantum. 


\section{DISCUSSION}

In the past both visceral and cutaneous leishmaniasis cases were recorded in Armenia, but since 1969 no case was registered until 1999. Presently, due to re-emergence of VL in Armenia, this disease became a major and on-going problem. Diagnosis of VL was based in Armenia until this study only on clinical picture and conventional microscopy of bone marrow aspirates and the causative agent has not been identified before to the species level. In the present study 25 clinically suspected VL cases were studied applying for the first time molecular diagnosis. In 22 of the 25 samples Leishmania DNA could be detected, showing that molecular approaches can be a reliable and sensitive method for Leishmania detection in Armenian settings. Moreover, the application of molecular methods allowed for the first time the identification of the causative agent of VL in Armenia at species level as L. infantum.

Similar trends and patterns of re-emergence and increase of incidence are currently observed in the whole Southern Caucasus region. Especially in Georgia there is a dramatic increase of VL cases in the last decade with 1919 registered cases from 1995 till 2010 and very high observed seroprevalences in pet and stray dogs as well as in humans (Babuadze et al., 2014). The first cases after a long break of approximately 30-40 years were registered in 1990 in Georgia and 1999 in Armenia. Tbilisi (in the East of Georgia) was identified as an old focus with many cases especially among adults, and Kutaisi (in the West of Georgia) as a new emerging focus with cases mainly among very young children. In Armenia most VL cases occurred in children in the age 1-3 years. First seroepidemiological studies conducted 2015 and 2016 in active Armenian VL foci (Yerevan, Armavir, Ararat, Lori, Tavush, Syunik) indicated that the seroprevalence in the $\sim 1200$ tested children under 10 years was rather low $(0.3 \%)$. In addition, seroprevalence in dogs was between 3-16\%, with the highest percentages in Tavush (16.1\%), Syunik (9.3\%) and Lori (6.5\%), stressing the potential of dogs as reservoir in these VL foci (Paronyan et al., 2017). Concerning bordering countries, such as Georgia, natural Leishmania foci are restricted mainly to the Eastern part of the country, some of them bordering to the north of Armenia (Lori and Tavush districts). In Azerbaijan, the most recent cases occur in the Northeast of the country bordering the Tavush district in Armenia but also in the central part and the south of the country (Alvar et al., 2012; Strelkova et al., 2015). Also the northwestern parts of Iran (East Azerbaijan and Ardabil) provinces bordering to the Syunik district are known as major endemic regions for VL showing also high seroprevalence in dogs (Abdinia et al., 2016; Barati et al., 2015; Soleimanzadeh et al., 1993). In Turkey, VL is endemic, and most cases occur at the Armenian border, in the Aegean, Mediterranean, and Central Anatolia Regions and dogs seem to be the main animal reservoir (Alvar et al., 2012). 
The reasons for the re-emergence of VL in these countries are not yet understood, however persisting rural foci (e.g. in the border regions between the Southern Caucasus countries) with growing populations of wild animal reservoirs as foxes and jackals, changing climate and increasing numbers of vectors, travelling and migration and a lack of surveillance and control measures might play a relevant role. It should be mentioned, that after the collapse of the USSR for a certain period surveillance and control of vectors and infected dogs was interrupted and has to be continuously re-organized.

ITS1-PCR is a highly sensitive molecular method for leishmaniasis diagnosis when compared with parasitological or serological techniques (Al-Jawabreh et al., 2006; el Tai et al., 2000; Schonian et al., 1996). Although results of the present study were obtained in a small sample set of previously microscopically confirmed VL cases, the diagnostic power and sensitivity of ITS1-PCR was demonstrated. The present study is a first and important step towards the implementation of modern molecular techniques in the current diagnosis of VL in Armenia. Because of the re-emergence of VL in different parts of Armenia and increasing prevalence in neighboring countries as Georgia, Azerbaijan, Turkey and Iran, molecular diagnostic laboratories with trained medical personal have to be established in Armenian health care centers to enable fast and reliable diagnosis and further control and surveillance measures. Currently there is a lack of such laboratories and trained medical or scientific personal. A first successful step in training local young scientists has been made in frame of the current study and the project, mentioned in the acknowledgment. Molecular methods can be applied in Armenia in future also for monitoring purposes by performing epidemiological surveys of humans and animal reservoirs, for prevalence studies and also for identification of infected sand flies as well as for sand fly typing.

Moreover, ITS1-PCR-RFLP and sequencing are useful tools for differentiation and identification of Leishmania species (Akhoundi et al., 2017; Kuhls et al., 2005; Schonian et al., 2003; Van der Auwera et al., 2016). The advantage of ITS1-PCR is that digestion of the amplicon by just one restriction enzyme (HaeIII) is sufficient to distinguish most medically relevant Leishmania species (Schonian et al., 2003). In the present work it could be proven that L. infantum is the causative agent of VL in Armenia showing identical ITS1 sequences as all other L. infantum strains from the Mediterranean region, the Middle East and Central Asia as well as the New World. Recently, L. infantum was also identified as causative agent of VL in Georgia by sequencing of the ITS region (Babuadze et al., 2016).

The ability to distinguish among Leishmania species is crucial when prescribing treatment, as well as in epidemiological studies to determine possible control measures (Schonian et al., 
2003). Further typing at intra-species level applying more discriminative molecular markers, such as microsatellites, may address epidemiological questions of VL in this region such as transmission cycles (identification of animal reservoirs and transmitting vectors), infection's origin and mode of spread in the Southern Caucasus, and the differentiation of indigenous from imported cases.

The present study constitutes the very first report on VL in Armenia in English including a historical overview of the disease, a report about re-emergence of the disease with case numbers and related epidemiological information as geographical distribution, as well as on the application of molecular diagnosis for VL and identification of the causative agent as $L$. infantum. The implementation of fast and sensitive diagnostic methods as well as further studies on prevalence of VL in animal reservoirs (dogs and wild animals) and humans and further entomological monitoring including vector control is urgently needed in Armenia taking into account that there is expected a considerable increasing risk for infections due to climate change. Recent simulation studies predicted a significant warming especially in the Southern Caucasus region with Armenia among the five countries of Eastern Europe and Central Asia that are mostly affected by hydro-meteorological phenomena that can result in a significant increase in vulnerability in relation to different infectious diseases such as malaria and leishmaniasis (Keshishyan et al., 2013b; Rajabi et al., 2017; Vermishev, 2010). In 2014 a joint initiative of the European Food Safety Authority (EFSA) and the European Centre for Disease Prevention and Control (ECDC) - VectorNet - started the establishment of a common database on the presence and distribution of vectors and pathogens in vectors in Europe and the Mediterranean basin, through a network of experts and organizations from the medical and veterinary field (https://vectornet.ecdc.europa.eu/). This initiative has allowed the support, among others, of East European and South Caucasus countries.

\section{CONCLUSION}

The present work represents the first report available in English about the re-emergence of visceral leishmaniasis in Armenia in 1999 after a long break of 30 years. It includes an epidemiological update as well as a detailed historical overview about VL in this country. In this study molecular diagnostic methods were implemented for the first time in Armenia for diagnosis of VL and as a result the causative agent was identified as Leishmania infantum. This work is an important step towards the inclusion of molecular techniques in the current diagnosis of VL in Armenia.

\section{ACKNOWLEDGMent}


The authors would like to thank Susanne Lobstein (Technical University of Applied Sciences Wildau) for experimental support.

\section{FINANCIAL SUPPORT}

The present study was supported by grants of the German Ministry of Education and Research (BMBF) (FKZ01DK14021, Central Asia - Southern Caucasus Leishmaniasis Project) and the German Academic Exchange Service (Deutscher Akademischer Austauschdienst - DAAD - Research grant 1618841).

\section{CONFLICT OF INTEREST}

The authors declare that there is no conflict of interest.

\section{Ethical considerations}

Study design and protocols were approved by the Ethical Committee of the Yerevan State Medical University after Mkhitar Heratsi (Approval Nr. 9, 01.07.2016). The aims of the study were explained to the responsible person of each minor and informed consent was obtained in written form. All samples were anonymized and laboratory codes were used for all experiments and data analysis. Demographic data (e.g. age, gender, place of residence) were collected from each patient for epidemiological purposes. 


\section{REFERENCES}

Abdinia, B., Oliaei-Motlagh, M. and Teimouri-Dereshki, A. (2016). Pediatric visceral leishmaniasis in northwest of Iran. Medicine (Baltimore), 95, e5261.

Akhoundi, M., Downing, T., Votypka, J., Kuhls, K., Lukes, J., Cannet, A., Ravel, C., Marty, P., Delaunay, P., Kasbari, M., Granouillac, B., Gradoni, L. and Sereno, D. (2017). Leishmania infections: Molecular targets and diagnosis. Mol Aspects Med, 57, 1-29.

Akhoundi, M., Kuhls, K., Cannet, A., Votypka, J., Marty, P., Delaunay, P. and Sereno, D. (2016). A Historical Overview of the Classification, Evolution, and Dispersion of Leishmania Parasites and Sandflies. PLoS Negl Trop Dis, 10, e0004349.

Al-Jawabreh, A., Schoenian, G., Hamarsheh, O. and Presber, W. (2006). Clinical diagnosis of cutaneous leishmaniasis: a comparison study between standardized graded direct microscopy and ITS1-PCR of Giemsa-stained smears. Acta Trop, 99, 55-61.

Alvar, J., Velez, I. D., Bern, C., Herrero, M., Desjeux, P., Cano, J., Jannin, J. and den Boer, M. (2012). Leishmaniasis worldwide and global estimates of its incidence. PLoS One, 7, e35671.

Babuadze, G., Alvar, J., Argaw, D., de Koning, H. P., losava, M., Kekelidze, M., Tsertsvadze, N., Tsereteli, D., Chakhunashvili, G., Mamatsashvili, T., Beria, N., Kalandadze, I., Ejov, M. and Imnadze, P. (2014). Epidemiology of visceral leishmaniasis in Georgia. PLoS Negl Trop Dis, 8, e2725.

Babuadze, G., Farlow, J., de Koning, H. P., Carrillo, E., Chakhunashvili, G., Murskvaladze, M., Kekelidze, M., Karseladze, I., Kokaia, N., Kalandadze, I., Tsereteli, D., Markhvashvili, I., Sidamonidze, K., Chanturia, G., Adeishvili, E. and Imnadze, P. (2016). Seroepidemiology and molecular diversity of Leishmania donovani complex in Georgia. Parasit Vectors, 9, 279.

Baranets, M. S., Darchenkova, N. N., Ponirovskii, E. N. and Zhirenkina, E. N. (2011). [The spread and epidemiological value of sandflies (Diptera, Psychodidae, Phlebotominae) of the Caucasus]. Med Parazitol (Mosk), 10-15.

Barati, M., Mohebali, M., Alimohammadian, M. H., Khamesipour, A., Akhoundi, B. and Zarei, Z. (2015). Canine visceral leishmaniasis: seroprevalence survey of asymptomatic dogs in an endemic area of northwestern Iran. J Parasit Dis, 39, 221-224.

Croft, S. L. and Olliaro, P. (2011). Leishmaniasis chemotherapy--challenges and opportunities. Clin Microbiol Infect, 17, 1478-1483. doi: 10.1111/j.1469-0691.2011.03630.x.

Darchenkova, N. N. and Dergacheva, T. I. (1989). [Patterns in the distribution of visceral leishmaniasis in Transcaucasia]. Med Parazitol (Mosk), 28-33.

Dergacheva, T. I. and Oganesian, I. A. (1987). [Present status of vector populations of the causative agent of leishmaniasis in Armenia]. Med Parazitol (Mosk), 31-34.

el Tai, N. O., Osman, O. F., el Fari, M., Presber, W. and Schonian, G. (2000). Genetic heterogeneity of ribosomal internal transcribed spacer in clinical samples of Leishmania donovani spotted on filter paper as revealed by single-strand conformation polymorphisms and sequencing. Trans $R$ Soc Trop Med Hyg, 94, 575-579.

Giorgobiani, E., Lawyer, P. G., Babuadze, G., Dolidze, N., Jochim, R. C., Tskhvaradze, L., Kikaleishvili, K. and Kamhawi, S. (2012). Incrimination of Phlebotomus kandelakii and Phlebotomus balcanicus as vectors of Leishmania infantum in Tbilisi, Georgia. PLoS Negl Trop Dis, 6, e1609.

Gishgorn, A. J. (1925). [A case of leishmaniasis in a child]. Russian Journal of Tropical Medicine, 4, 47.

Gurko, A. G. (1913). [Four cases of Kala-azar disease]. Medical Review, 79, 346-348.

Isaev, L. M. (1959). [Eradication of leishmaniasis in the USSR during the 7-year-plan]. Med Parazitol (Mosk), 28, 323-327.

Isaev, L. M. and Ryabtsev, F. I. (1958). [Pathogenesis of visceral leishmaniasis in dogs]. Transactions of the Institute of Malaria and Medical Parasitology of Uzbekistan (Samarkand) [Trudy Uzb Inst Malarii i Med Parasitol (Samarkand)], 3, 51.

Isahakyan, A. I. (1924). [Human and canine leishmaniasis in Armenia and neighboring countries]. Transactions of the Armenian Tropical Institute [Trudy Trop Inst Armenii], 1, 115-138. 
Karagezian, L. A. (1966). [Cutaneous leishmaniasis (Borovskii's disease) in Armenia]. Vestn Dermatol Venerol, 40, 61-64.

Karapetyan, R. M. (1949). [The case of visceral leishmaniasis in an adult in Yerevan]. Transactions of the Institute of Malaria and Medical Parasitology [Trudy Inst Malarii i Med Parasitol], 4, 152 156.

Karapetyan, R. M. (1972). [A source of invasion and the natural focality of visceral leishmaniasis in the Armenian SSR]. Med Parazitol (Mosk), 41, 444-448.

Karapetyan, R. M. and Baghdasaryan, A. B. (1970). [Nosogeography of leishmaniasis in the Armenian SSR]. Journal of Experimental and Clinical Medicine, 10, 91-95.

Karapetyan, R. M. and Baghdasaryan, A. B. (1972). [On the question of distribution of leishmaniasis in Transcaucasia]. Med Parazitol (Mosk), 3, 291-297.

Karapetyan, R. M., Petrosyan, N. A., Mnatsakanyan, S. S. and Avetisyan, A. G. (1960). [Experiences in the control of visceral leishmaniasis in the city of Yerevan]. Med Parazitol (Mosk), 6, 665-670.

Karapetyan, R. M., Vopyan, D. S. and Mnatsakanyan, S. S. (1970). [Current problems in medical parasitology and and tropical medicine] Tbilisi.

Keshishyan, A., Grigoryan, O. R., Manukyan, D. V. and Hovsepyan, A. A. (2013a). [Reported cases of Leishmaniasis in Nagorno-Karabach]. In Recent questions in epidemiology (ed. Research Institute of Epidemiology, V. a. M. P. a. A. B. A., Ministry of Health, Yerevan, Armenia), pp. 132-134. Research Institute of Epidemiology, Virology and Medical Parasitology after A.B. Alexanyan, Ministry of Health, Yerevan, Armenia, Yerevan, Armenia.

Keshishyan, A., Manukyan, D. V. and Melik-Andreasyan, G. (2013b). Climate change and the problem of Malaria in Armenia. World Academy of Science, Engineering and technology, 75.

Keshishyan, A. S. and Manukyan, D. V. (2003). [Improvement of the epidemiological surveillance of leishmaniasis considering the climate changes in Armenia]. In [Armenia: challenges of the climate change] pp. 237-241.

Kovalenko, D. A., Razakov, S. A., Ponirovsky, E. N., Warburg, A., Nasyrova, R. M., Ponomareva, V. I., Fatullaeva, A. A., Nasereddin, A., Klement, E., Alam, M. Z., Schnur, L. F., Jaffe, C. L., Schonian, G. and Baneth, G. (2011). Canine leishmaniosis and its relationship to human visceral leishmaniasis in Eastern Uzbekistan. Parasit Vectors, 4, 58.

Kuhls, K., Mauricio, I. L., Pratlong, F., Presber, W. and Schonian, G. (2005). Analysis of ribosomal DNA internal transcribed spacer sequences of the Leishmania donovani complex. Microbes Infect, 7, 1224-1234.

Mamikonyan, M. M. (1935). [Canine leishmaniasis in Yerevan]. Transactions of the Veterinary Research Institute of Armenia [Trudy Nauch Islied Vet Inst Armenii], 2, 183-185.

Meredith, S. E., Zijlstra, E. E., Schoone, G. J., Kroon, C. C., van Eys, G. J., Schaeffer, K. U., el-Hassan, A. M. and Lawyer, P. G. (1993). Development and application of the polymerase chain reaction for the detection and identification of Leishmania parasites in clinical material. Arch Inst Pasteur Tunis, 70, 419-431.

Millan, J., Ferroglio, E. and Solano-Gallego, L. (2014). Role of wildlife in the epidemiology of Leishmania infantum infection in Europe. Parasitol Res, 113, 2005-2014. doi: 10.1007/s00436014-3929-2.

Mirzoyan, A. A. (1941). [About the epidemiology of cutaneous leishmaniasis in the Gorish region of the Armenian SSR] Journal of the Soviet Health Care of Turkmenistan, 1-2, 68-80.

Paronyan, L., Apresyan, H., Avetisyan, G., Tunyan, A., Gevorgyan, K., Babyan, L. and Vanyan, A. (2017). Visceral Leishmaniasis as re-emerging problem in Armenia, seroepidemiological study, 2015-2016. In In: Abstracts book - 6th World Congress on Leishmaniasis, 16-20 May, Abstract C2059 pp. p. 1462 . Toledo, Spain.

Paronyan, L., Apresyan, H., Galstyan, A., Keshishyan, A. and Vanyan, A. (2015). Trends in visceral leishmaniasis in Armenia. In International Conference on Emerging Infectious Diseases pp. 221222. Atlanta, USA.

Pirumov, K. N. (1957). [Materials for promoting control of parasitic diseases in Armenian SSR]. Med Parazitol (Mosk), 5, 578-581. 
Rajabi, M., Pilesjo, P., Bazmani, A. and Mansourian, A. (2017). Identification of Visceral Leishmaniasis-Susceptible Areas using Spatial Modelling in Southern Caucasus. Zoonoses Public Health, 64, e5-e22.

Ready, P. D. (2014). Epidemiology of visceral leishmaniasis. Clin Epidemiol, 6, 147-154. doi: $10.2147 /$ clep.S44267.

Saladze, I. (1964). [Geographical distribution of sand flies in Georgia]. Transactions of the Virsaladze Institute of Parasitology and Tropical Medicine [Trudy Inst Parazitol i Trop Med im. Virzaladze], 5, 261-265.

Schonian, G., Kuhls, K. and Mauricio, I. L. (2011). Molecular approaches for a better understanding of the epidemiology and population genetics of Leishmania. Parasitology, 138, 405-425.

Schonian, G., Nasereddin, A., Dinse, N., Schweynoch, C., Schallig, H. D., Presber, W. and Jaffe, C. L. (2003). PCR diagnosis and characterization of Leishmania in local and imported clinical samples. Diagn Microbiol Infect Dis, 47, 349-358.

Schonian, G., Schweynoch, C., Zlateva, K., Oskam, L., Kroon, N., Graser, Y. and Presber, W. (1996). Identification and determination of the relationships of species and strains within the genus Leishmania using single primers in the polymerase chain reaction. Mol Biochem Parasitol, 77, 19-29.

Soleimanzadeh, G., Edrissian, G. H., Movahhed-Danesh, A. M. and Nadim, A. (1993). Epidemiological aspects of kala-azar in Meshkin-Shahr, Iran: human infection. Bull World Health Organ, 71, 759-762.

Steverding, D. (2017). The history of leishmaniasis. Parasit Vectors, 10, 82.

Strelkova, M. V., Ponirovsky, E. N., Morozov, E. N., Zhirenkina, E. N., Razakov, S. A., Kovalenko, D. A., Schnur, L. F. and Schonian, G. (2015). A narrative review of visceral leishmaniasis in Armenia, Azerbaijan, Georgia, Kazakhstan, Kyrgyzstan, Tajikistan, Turkmenistan, Uzbekistan, the Crimean Peninsula and Southern Russia. Parasit Vectors, 8, 330.

Sukiasyan, A., Keshishyan, A., Manukyan, D., Malik-Andreasyan, G., Atshemyan, L., Frohme, M., Cortes, S. and Kuhls, K. (2017). Visceral Leishmaniasis in Armenia - first time use of molecular diagnosis. In In: Abstracts book - 6th World Congress on Leishmaniasis, 16-20 May, Abstract C0753, Vol. Abstract C0753 pp. 1389. Toledo, Spain.

Van der Auwera, G., Bart, A., Chicharro, C., Cortes, S., Davidsson, L., Di Muccio, T., Dujardin, J. C., Felger, I., Paglia, M. G., Grimm, F., Harms, G., Jaffe, C. L., Manser, M., Ravel, C., RobertGangneux, F., Roelfsema, J., Toz, S., Verweij, J. J. and Chiodini, P. L. (2016). Comparison of Leishmania typing results obtained from 16 European clinical laboratories in 2014. Euro Surveill, 21. doi: 10.2807/1560-7917.Es.2016.21.49.30418.

Vermishev, M. (2010). [Pecularities of the economic development in Armenia in the context of climate change] In On the way to Copenhagen. Armenia ahead of the 15th Conference of the Parties on Climate Change pp. 21-22. Yerevan.

WHO (2010). Control of the leishmaniases. World Health Organ Tech Rep Ser, xii-xiii, 1-186, back cover.

WHO (2015). Investing to overcome the global impact of neglected tropical diseases: third WHO report on neglected tropical diseases. . Geneva, Switzerland.

Wright, J. H. (1903). Protozoa in a Case of Tropical Ulcer ("Delhi Sore"). J Med Res, 10, 472-482 477. 
Table 1. Designation, characteristics, origin and diagnostic results of the Armenian samples studied.

\begin{tabular}{|c|c|c|c|c|c|c|c|c|}
\hline $\begin{array}{l}\text { Patients } \\
\text { labcode }\end{array}$ & $\begin{array}{c}\text { Year of } \\
\text { collection }\end{array}$ & $\begin{array}{l}\text { Age } \\
\text { [years] }\end{array}$ & Gender & District & Locality & $\begin{array}{c}\text { Micro- } \\
\text { scopy }\end{array}$ & $\begin{array}{l}\text { ITS1- } \\
\text { PCR }\end{array}$ & $\begin{array}{c}\text { ITS1-PCR } \\
\text { RFLP } \\
\text { identification }\end{array}$ \\
\hline Arm1 & 2013 & 1.5 & male & Syunik & Goris city & negativ & negative & n.d. \\
\hline Arm2 & 2013 & 51 & male & Syunik & Goris & negativ & negative & n.d. \\
\hline Arm3 & 2013 & $\begin{array}{l}9 \\
\text { months }\end{array}$ & female & Syunik & Kapan & positiv & positive & L. infantum \\
\hline Arm4 & 2013 & 1 & male & Syunik & Kapan & negativ & negative & n.d. \\
\hline Arm5 & 2014 & 3.2 & female & Syunik & Karaundj & positiv & positive & L. infantum \\
\hline Arm6 & 2012 & 2 & female & Syunik & Kapan & positiv & positive & L. infantum \\
\hline Arm7 & 2013 & 0.9 & male & Syunik & Kapan & positiv & positive & L. infantum \\
\hline Arm8 & 2012 & 12 & male & Lori & Achthala & positiv & positive & L. infantum \\
\hline Arm9 & 2012 & 1.8 & female & Yerevan & Nor Nork & positiv & positive & L. infantum \\
\hline Arm 10 & 2014 & 1.7 & male & Tavush & Baganis & positiv & positive & L. infantum \\
\hline Arm11 & 2014 & 1 & female & Tavush & Baganis & positiv & positive & L. infantum \\
\hline Arm12 & 2015 & 3.3 & female & Armavir & Hoktember & positiv & positive & L. infantum \\
\hline Arm13 & 2015 & 2.5 & male & Syunik & Kapan & positiv & positive & L. infantum \\
\hline Arm14 & 2015 & 5 & female & Syunik & Kapan & positiv & positive & L. infantum \\
\hline Arm15 & 2015 & 1.5 & male & Yerevan & $\begin{array}{l}\text { Chorenaci } \\
\text { ctr }\end{array}$ & positiv & positive & L. infantum \\
\hline Arm16 & 2015 & 2 & female & Yerevan & & positiv & positive & L. infantum \\
\hline Arm17 & 2015 & 2 & male & Yerevan & Kanaker & positiv & positive & L. infantum \\
\hline Arm18 & 2015 & 2 & male & Yerevan & $\begin{array}{l}\text { Tcarav } \\
\text { Aghbyur }\end{array}$ & positiv & positive & L. infantum \\
\hline Arm19 & 2015 & 2 & female & Kotayk & Abovyan & positiv & positive & L. infantum \\
\hline Arm20 & 2015 & 2.8 & male & Syunik & Goris & positiv & positive & L. infantum \\
\hline Arm21 & 2014 & 2.8 & female & Syunik & Goris & positiv & positive & L. infantum \\
\hline Arm22 & 2013 & 2 & male & Syunik & Goris & positiv & positive & L. infantum \\
\hline Arm23 & 2016 & 3 & female & Tavush & Idjevan & positiv & positive & L. infantum \\
\hline Arm24 & 2016 & 1 & male & Tavush & Koti & positiv & positive & L. infantum \\
\hline Arm25 & 2016 & 1 & male & Tavush & Koti & positiv & positive & L. infantum \\
\hline
\end{tabular}


Figure 1. (A) Number of indigenous and imported cases of visceral leishmaniasis in Armenia per year in the period 1999-2016. In total 116 indigenous and 99 imported VL cases were recorded. (B) Map of the Southern Caucasus region with Armenia and the bordering countries. (C) Map showing the distribution of the 116 indigenous cases in the affected districts of the country (black numbers). Red dots indicate the studied 22 cases of visceral leishmaniasis from the time period 2012-2016 in Armenia. (D) Percentage per district relative to the total number of 116 indigenous VL cases in the country.

Figure 2. ITS1-PCR-RFLP of ITS1 with HaeIII of reference strains and representative clinical samples of the Armenian studied cases. M, pUC19 DNA size marker; 1-3, WHO-reference strains: 1, L. major MHOM/SU/1973/5ASKH; 2, L. tropica MHOM/SU/1974/SAF-K27; 3, L. infantum MHOM/ES/1993/PM1; 4, ITS1 undigested clinical sample; 5, Arm8; 6, Arm3; 7, Arm5; 8, Arm6; 9, Arm7; 10, Arm9; 11, Arm10 


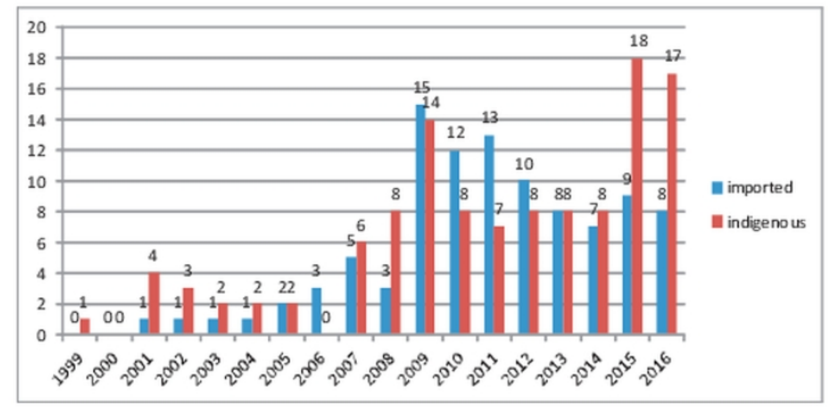

A

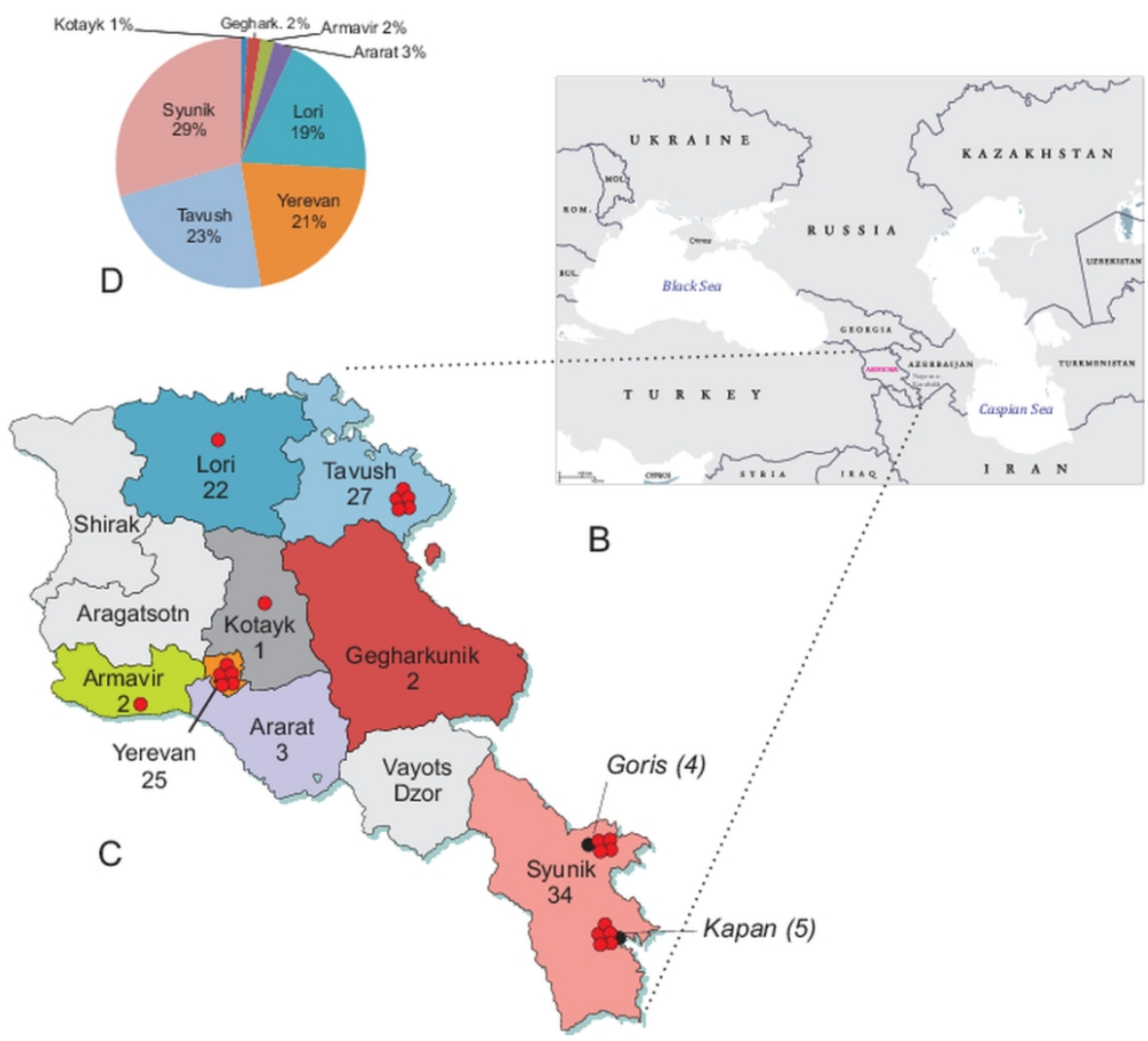

Figure 1. (A) Number of indigenous and imported cases of visceral leishmaniasis in Armenia per year in the period 1999-2016. In total 116 indigenous and 99 imported VL cases were recorded. (B) Map of the Southern Caucasus region with Armenia and the bordering countries. (C) Map showing the distribution of the 116 indigenous cases in the affected districts of the country (black numbers). Red dots indicate the studied 22 cases of visceral leishmaniasis from the time period 2012-2016 in Armenia. (D) Percentage per district relative to the total number of 116 indigenous VL cases in the country.

$165 \times 220 \mathrm{~mm}(300 \times 300 \mathrm{DPI})$ 


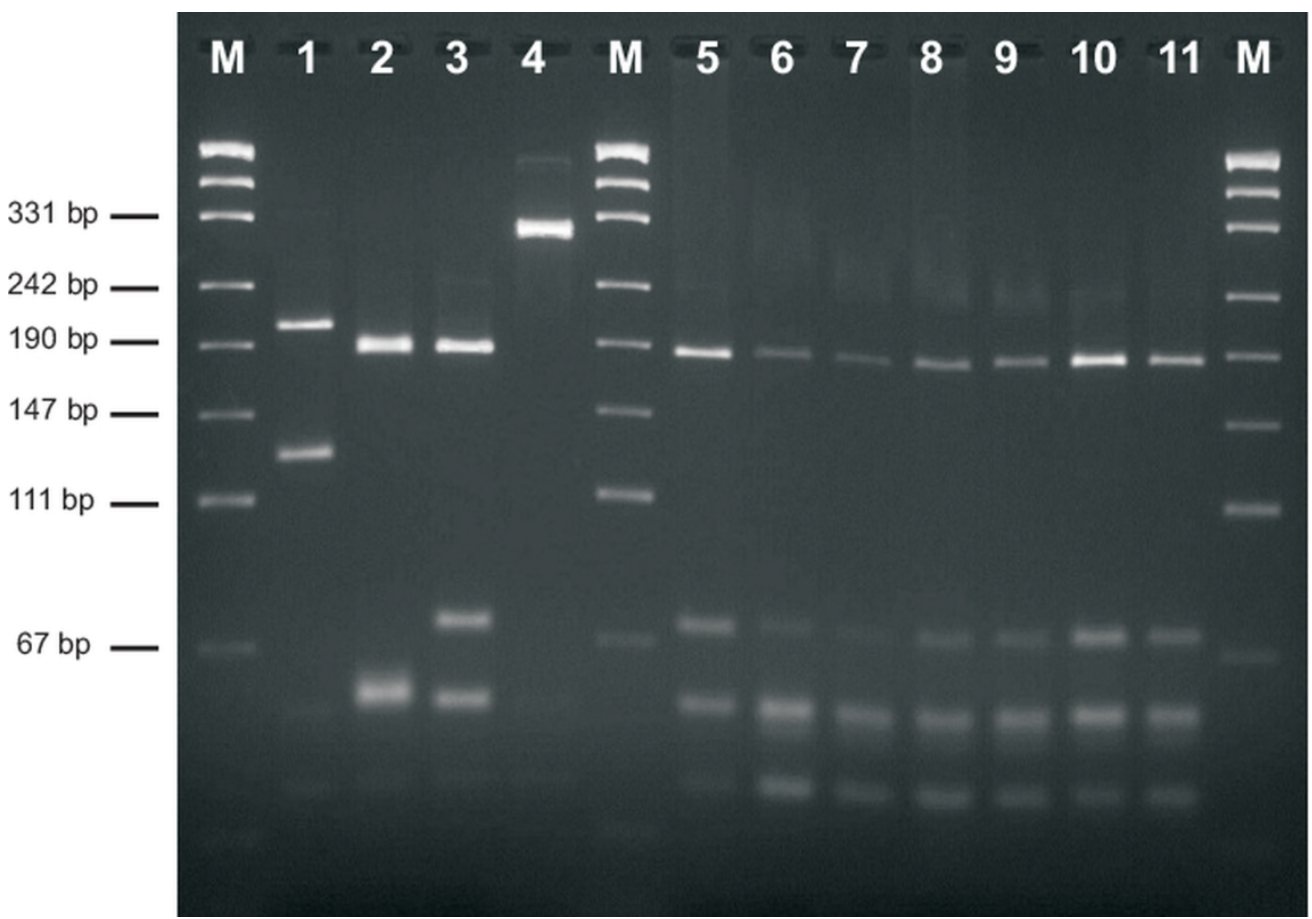

Figure 2. ITS1-PCR-RFLP of ITS1 with HaeIII of reference strains and representative clinical samples of the Armenian studied cases. M, pUC19 DNA size marker; 1-3, WHO-reference strains: 1, L. major MHOM/SU/1973/5ASKH; 2, L. tropica MHOM/SU/1974/SAF-K27; 3, L. infantum MHOM/ES/1993/PM1; 4, ITS1 undigested clinical sample; 5, Arm8; 6, Arm3; 7, Arm5; 8, Arm6; 9, Arm7; 10, Arm9; 11, Arm10 $165 \times 115 \mathrm{~mm}(300 \times 300$ DPI $)$ 